\title{
Bubble Dynamics in a Diesel Exhaust Wet Scrubber
}

\author{
A. Abdulwahid ${ }^{1,2}$, R. Situ', R. Brown ${ }^{3}$, and W. Lin 1 \\ ${ }^{1}$ College of Science and Engineering \\ James Cook University, Townsville QLD 4811, Australia \\ ${ }^{2}$ Al-Nahrain University, Baghdad, 10072, Iraq \\ ${ }^{3}$ School of Mechanical Medical \& Process Engineering
}

Biofuel Engine Research Facility, Queensland University of Technology, Brisbane QLD 4000, Australia

\begin{abstract}
A wet scrubber is an air pollution removal device that eliminates particulate matter and acid gases from a diesel engine. The exhaust gas enters the scrubber beneath the liquid surface, causing a reduction in gas temperature and increases the relative humidity of scrubber outlet. In this study, bubble motion was captured with a high-speed video system in 16 test conditions. Heat transfer analysis was used to investigate the direct interaction between the bubbles and their surrounding liquid. The experimental results confirmed that there are three flow regions at the low inlet gas flow rate: inlet, bulk and exit region (at exit). At the departing region, the bubble diameter depended on the inlet gas volumetric flow rate. The bubble number ratio was a function of the inlet gas Reynolds number. The heat transfer between the bubbles and liquid depended on the inlet gas temperature ratio.
\end{abstract}

\section{Keywords}

Wet Scrubber, Bubble Dynamics, Heat transfer, Gas-Liquid Two-phase flow.

\section{Introduction}

The wet scrubber is a device used to eliminate the pollution of the exhaust gases from diesel engines, in particular for underground equipment. Both thermal and chemical reactions occur within the scrubber between the bubbles of the gas-phase and the surrounding scrubbing liquid-phase. The temperature difference between bubbles and liquid leads to thermal reaction. This type of reaction depends on bubble size, motion and position. The chemical reaction occurs as a result of dissolving some soluble gases in the liquid. Indeed, Abdulwahid et al. [1] reviewed the heat and mass transfer in this type of wet scrubber. This paper investigates the heat transfer mechanism within the wet scrubber without including the mass transfer between bubbles and liquid due to evaporation or/and condensation.

\section{Experimental setup}

The experiments were conducted with a laboratory apparatus shown in figure 1. This apparatus consists of a scrubber tank, a gas-phase supply, an industrial air blower, a high-speed video camera system and other instruments such as thermocouples and a humidity probe [2]. Compressed air, controlled through air flowmeters with possible error \pm 5.6 SLPM, was fed through an air blower and a 50-mm-diamter inlet pipe and entered at the bottom of the scrubber tank. Next, air bubbles pass through a plate with one row of round orifice holes $(4 \times 5 \mathrm{~mm}, 4 \times 7.5 \mathrm{~mm}$, or $3 \times 10 \mathrm{~mm}$ in diameter $)$.

The experimental conditions consisted of 16 tests, with inlet gas Reynolds number (Re) varying between 1200, 1800, 2400 and 3300 (corresponding to gas volume flow rate of 115 , 170, 225, and 285 SLPM, respectively), inlet gas temperature ratio $\left(\theta \equiv T_{\text {inlet }} / T_{\text {ambient }}\right.$, in Kelvin) varying from 1.0 to 3.0 and orifice ratio $\left(\beta \equiv d_{\text {orifice }} / d_{\text {pipe }}\right)$ of $0.1,0.15$ or 0.2 . Both liquid volume ratio and the liquid temperature were maintained constant at $42 \%$ and $20^{\circ} \mathrm{C}$ respectively to eliminate their possible effects on the wet scrubber investigation. The measurement accuracy temperature measurement is $\pm 0.5^{\circ} \mathrm{C}$, while the flowrate error is \pm 5.6 SLPM for the 283 SLPM flow meter. Monitoring bubbles became simpler and more accurate using the orifice plate. Therefore, three sizes of orifice were tested to find their possible effect of this size on the bubble formation.

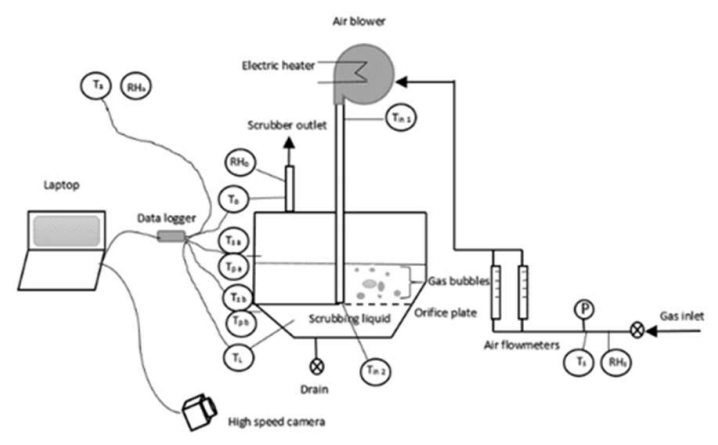

Figure 1. A wet scrubber schematic diagram.

A high-speed video system was used to record videos and images. The captured videos and images were analysed using ImageJ software Version 1.51j8. Information of bubbles such as their position, area, orientation, and circularity were obtained after detecting bubbles with red numbers, as shown in the next section.

\section{Flow Characteristics Observation}

At low inlet gas flux, the bubble path can be classified into three regions, i.e., inlet, bulk, and exit regions, as indicated in Figure 2(a). However, for high inlet gas Reynolds numbers, bubble motion was extremely violent and only the churn-turbulent region could be recognised. 


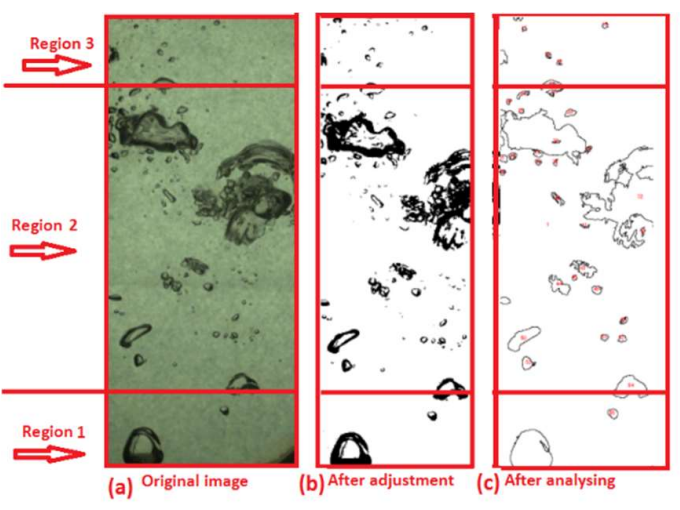

Figure 2. Image processing using ImageJ software.

Table 1 shows the average percentage of these three regions for the three orifice ratios over the total liquid height for all tests.

\begin{tabular}{ccccc}
\hline $\operatorname{Re}$ & $\theta$ & \multicolumn{3}{c}{ Height ratio (\%) } \\
\hline 1200 & $\begin{array}{c}1,1.3,2, \\
2.6,3\end{array}$ & 23 & 55 & 22 \\
\hline 1800 & 1 & 20 & 62 & 18 \\
\hline 2400 & 1 & 17 & 70 & 13 \\
\hline 3300 & 1 & 0.0 & 100 & 0.0 \\
\hline
\end{tabular}

Table 1. Average height ratio for three regions at low inlet gas flow rate.

\section{Region 1: Inlet Region}

The first region of the wet scrubber flow was located directly above the orifice, and it contained bubbles with clear recognition. These bubbles were defined as parent or mother bubbles, and they moved upward. Their growth was smooth for the low inlet gas Reynolds number. At this case, maximum bubble size occurred after a short time directly above the orifice. This maximum bubble size also was a function of the orifice ratio: for example, the large one had produced larger bubbles than the smaller orifice ratio. Most bubbles travelled separately from the others without breaking or overlapping. This region was limited vertically from the orifice until the next region, and it was influenced by the inlet gas flow rate. For example, its height was found about $23 \%$ of the total liquid height at inlet gas Reynolds number of 1,200. The region height was much less than that for the higher inlet gas Reynolds number. This region was independent of the liquid volume ratio and the inlet gas temperature. ImageJ confirmed that the next region started when the bubbles cannot be recognised separately because of a high percentage of bubble overlapping.

\section{Region 2: Bulk Region}

The second region was located downstream and upward of the departing region directly. The bubbles were very churnturbulent and shaped rapidly. This churn-turbulent region can be recognised by the area where bubbles start overlapping, breaking up and coalescence. This region contained both large bubbles due to coalescence, and small bubbles as the result of bubble breakup. Some bubbles from the inlet region may also be present. These bubbles were in continuous change of shape and size. A high percentage of bubbles were observed overlapping in this region. Most important, turbulence dominates in this region. This is a good agreement with Clift $e t$ al. [3] who suggested that in multiphase flow equipment, the bubbles' size distribution is led by the bubble breakup and coalescence dynamics. These bubbles moved upward towards the liquid surface or/and in a horizontal direction towards the interior scrubber sides. At high inlet gas Reynolds number, the bubble travel time from orifice to liquid surface was very short. Therefore, the formation of this region depended strongly on the inlet gas Reynolds number and liquid volume ratio. However, this formation was independent of the orifice ratio.

\section{Region 3: Exit Region}

The third region of the flow in the wet scrubber was located between the bulk region and the liquid surface. The appearance of this region was dominated by turbulence also. This region started when ImageJ recognised most bubbles without overlapping upward region 2 . This means that this point was the first boundary of this region and it was limited by the liquid surface. It contained small bubbles from the break-up of big bubbles in region two. These bubbles were defined as the outlet or daughter bubbles. Most of these bubbles burst at the liquid surface with temperatures equal to the outlet gas temperature. However, some of these small bubbles were moved horizontally and/or downward towards the interior sides of the scrubber due to the flow turbulence effect. This means all bubbles burst out at the low inlet gas Reynolds number. Moreover, this region was independent of the orifice ratio, the liquid volume ratio and the inlet gas temperature ratio.

\section{Methodology}

\section{Assumptions}

Some assumptions should be considered to analyse the heat transfer in the wet scrubber. First, the bubble contents are homogeneous. Therefore, the temperature and the pressure within the bubble are always uniform. The gas inside the bubble is only air and it assumed to follow the gas law [4]. Further, the fluid properties are constant, with no radial (or tangential) change of properties/concentrations. Although the fluid compressibility can be important in bubble collapse, it is be assumed constant $[4,5]$. Most importantly, the events occur too rapidly for significant mass transfer of the contaminant gas to occur between the bubble and the surrounding liquid. This means no mass transfer between the bubble and the surrounding liquid. Finally, the effect of scattered bubbles was neglected.

\section{Output Parameters from Image Analysis}

Bubble motions were recorded as images and videos using a high-speed video system. Both images and videos were processed effectively using ImageJ software. The investigated parameters from the image analysis are: bubble Sauter mean diameter, bubble velocity, bubble heat transfer coefficient, mother to daughter bubble ratio, and bubble circularity. These parameter can be calculated as:

Bubble size: To calculate the bubble size in region 1, ImageJ software provided the projected area (AP) of any detected bubble. The projected area is the two-dimensional measured area of the three-dimensional object. Then, the equivalent bubble diameter can be calculated with $d_{e}=\sqrt{4 A_{p} / \pi}$. The averaged bubble size is calculated with the Sauter Mean Diameter (SMD, $d_{32}$ or $\left.\mathrm{D}[3,2]\right)[6]$

$$
d_{32}=\sum_{i=1}^{i=N} d_{e i}^{3} / \sum_{i=1}^{i=N} d_{e i}^{2}
$$

The non-dimensional bubble $\operatorname{size}\left(\beta_{b}\right)$ is related to orifice size $\left(d_{o}\right)$ : 


$$
\beta_{b}=d_{32} / d_{o}
$$

Bubble velocity: The bubble vertical velocity $\left(u_{b}\right)$ was obtained by calculating the change in y-position of the bubble centroid in consecutive image frames. This process was applied for $70+$ different bubbles within region 1 for each test to obtain the averaged bubble velocity

$$
u_{b}=\sum_{i=1}^{i=N}\left(\frac{y_{i 2}-y_{i 1}}{t_{i}}\right) / N,
$$

where: $y_{i l}, y_{i 2}$ are the bubble y positions in image frame 1 and 2 respectively, and $t_{i}$ is the bubble travelling time from $y_{i l}$ to $\mathrm{y}_{i 2}$.

The bubble Reynolds number can be calculated by:

$$
\operatorname{Re}_{b}=u_{b} d_{32} \rho_{b} / \mu_{b}
$$

Mother-to-daughter bubble number ratio: Bubbles left the orifices at the inlet region and travelled upward with a certain total number of bubbles based on the inlet gas Reynolds number. The number of these bubbles changed dramatically in the churn-turbulent region (Region 2) due to bubble coalescence and breaking-up. These bubbles broke up further to smaller bubbles in the exit region (Region 3 ). The mother-todaughter bubbles number ratio $(\lambda)$ will affect the heat transfer between the bubbles and the liquid.

$$
\lambda=\sum N_{1} / \sum N_{3} .
$$

This bubble number ratio was obtained from ImageJ software by counting the bubble numbers for each region in the image files.

Bubble Heat Transfer: Bubble temperature drops continuously with the liquid height because of changing surface area and temperature difference. This reduction in bubble temperature continues until reaching the outlet gas temperature when bubbles burst at the liquid surface. However, the unsteady bubble motion make the estimation of the bubble heat transfer challenging [4]. The relationship between the bubbles and their position is very complex because the bubbles might lose more energy horizontally than vertically. To simplify the calculation, it was assumed that the bubble temperature changed linearly with its y-position only:

$$
T_{b i n, j}=T_{i n 2}-\frac{y_{k}}{H}\left(T_{i n 2}-T_{o}\right),
$$

where: $T_{b i n, j}$ is bubble temperature at the inlet of region $j(=1,2,3)$, $T_{i n 2}$ is the inlet gas temperature at the pipe outlet, $T_{o}$ is the leaving liquid bubble temperature, $H$ is the total liquid height, and $y_{j}$ is the bubble y-location of the region.

The heat transferred from the gas-phase to the liquid phase in any region $(1,2$, or 3$)$ can be calculated from [1].

$$
Q_{j}=\dot{m}_{g} c_{p g}\left(T_{b i n, j+1}-T_{b i n, j}\right)
$$

where: $Q_{j}$ is the heat loss of bubbles in any region, $\dot{m}_{g}$ is the gas mass flow rate, $c_{p g}$ is the gas thermal capacity.

Hart [7] explained that the heat transfer coefficient was independent of several parameters such as the liquid height, column diameter and bubble location within the liquid. Therefore, it is assumed that it is independent of the liquid height, bubble' diameter and location within the region. In this study, an averaged heat transfer coefficient is representing each of the three regions, and it shall satisfy this equation:

$$
Q_{j}=h_{j} A_{b, j}\left(T_{b j}-T_{L}\right)
$$

where: $h_{j}$ is the heat transfer coefficient between the bubbles and their surrounding liquid, $A_{b, j}$ is the total bubble surface area in any region,
$T_{b, k j}$ is the average bubble temperature of the flow region and $T_{L}$ is the liquid temperature.

The averaged heat transfer coefficient for each region can be calculated from equations (7) and (8). These average heat transfer coefficients of all regions can be used to estimate the averaged Nusselt number $(\mathrm{Nu})$ of the scrubber:

$$
N u=\frac{\bar{h}_{j} d_{32}}{k}=\left(\frac{\mathrm{h}_{1}+\mathrm{h}_{2}+\mathrm{h}_{3}}{3}\right) \frac{d_{32}}{k}
$$

\section{Results and discussions}

\section{Effect of the Orifice Ratio}

The orifice plate played an important and positive role for the scrubber performance. It influenced both the flow turbulence and the liquid carried by the outlet gas. The inertia and pressure forces at the three or four adjacent orifices affected the sizes, shapes and velocities of emerging bubbles.

The vertical bubble velocity at Region 1 decreased with increasing the orifice size, as shown in figure 3. This can be explained easily using the mass continuity equation. To maintain the same mass flow rate of the inlet gas, the increment in the orifice cross-sectional area is correspond to a reduction in the bubble velocity.



Figure 3. The bubble Reynolds number with orifice ratio in region 1.

\section{Effect of the Inlet Gas Reynolds Number}

The inlet gas Reynolds number has a major effect on the flow dynamics and the heat transfer in the scrubber. Experiments with four inlet-gas Reynolds numbers of $1,200,1,800,2,400$ and 3,300 were studied. However, high bubble overlapping ratio in the last condition make the image analysis highly complex so this condition is ignored. The experiments maintained the inlet gas temperature ratio, the liquid temperature and the orifice ratio were maintained constant at 1 , $20^{\circ} \mathrm{C}$ and 0.1 , respectively to eliminate their effect.

The bubble Reynolds number of Region 1 is plotted against inlet gas Reynolds number in Figure 4. The bubble Reynolds number it is the product of bubble size and bubble velocity. Experiments found that the bubble velocities remained constant in these three test conditions. Hence the bubble Reynolds number is mainly dependent on bubble size. The bubble diameter first decreased with the increasing of the inlet gas flow rate, because many big bubbles were not detected by ImageJ due to bubble overlapping and/or coalescence. The latter increase of bubble diameter is mainly due to the increase of inlet gas volumetric flow rate. 


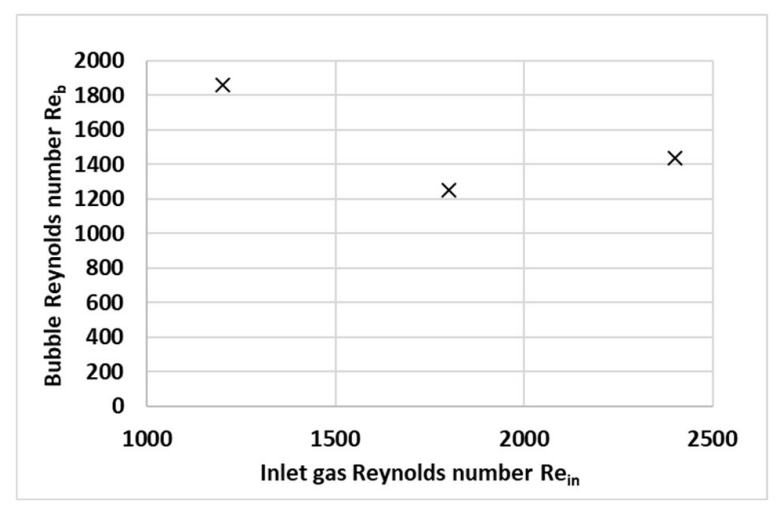

Figure 4. Dimensionless bubble diameter in Region 1 against inlet gas Reynolds number.

Mother-to-daughter bubble ratio $(\lambda)$ depended strongly on the inlet gas Reynolds number, as shown in Figure 5. Higher turbulence was observed clearly at the higher inlet gas Reynolds number. This lead to the increase of bubble break-up. The latter reduction of bubble ratio is because bubble coalescence in Region 3 led difficulties in bubble recognition at higher gas flow rate.

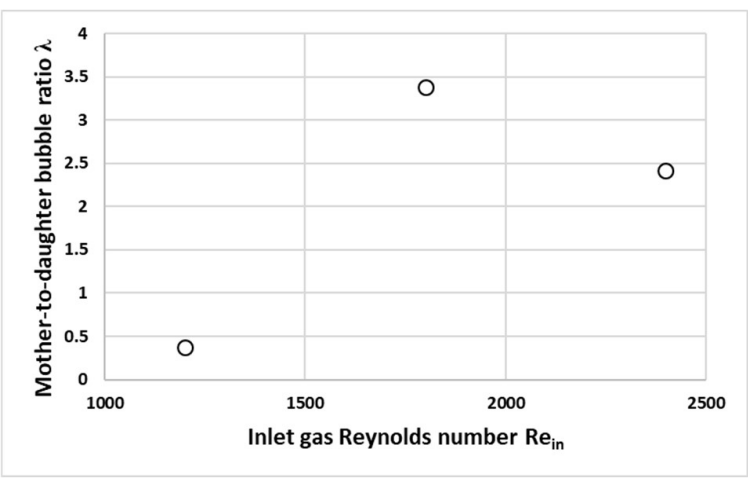

Figure 5. Mother-to-daughter number bubble ratio against inlet gas Reynolds number.

\section{Effect of the Inlet gas Temperature Ratio}

The effect of increasing the inlet gas temperature ratio on scrubber performance was investigated at a constant liquid temperature of $20^{\circ} \mathrm{C}$. Both the inlet gas Reynolds number and the orifice ratio were maintained constant at 1,200 and 0.1 , respectively. This section investigates the four inlet gas temperature ratios of $1.3,2,2.6$ and 3 on the bubble characteristics hydro-dynamically and thermally.

The non-dimensional form of the relationship between the average heat transfer coefficient and the inlet gas temperature can be expressed in terms of the Nusselt number and the inlet gas temperature ratio. The calculated Nusselt number increased due to increasing the inlet gas temperature ratio, shown in Figure 6. This can be a result of the increase in the heat transfer coefficient and bubble velocity with temperature.

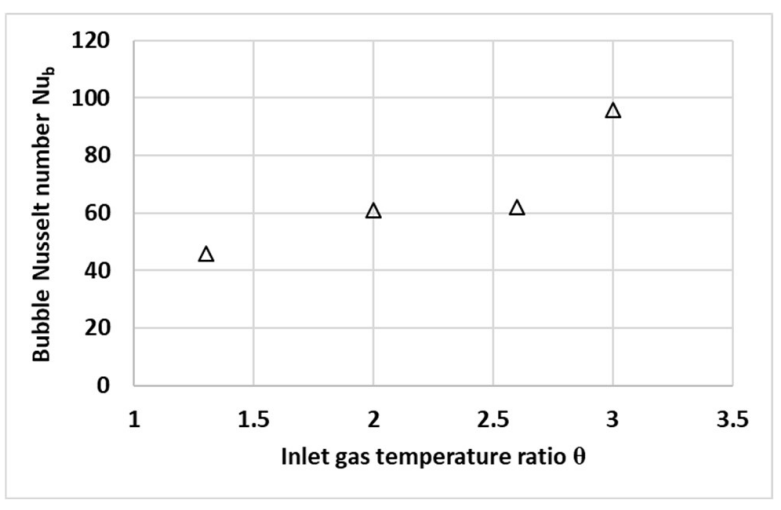

Figure 6. Bubble heat transfer Nusselt number as a function of inlet gas temperature ratio.

\section{Conclusion}

Bubble dynamics and heat transfer in the wet scrubber was studied with image analysis under different operating condition. The experimental results confirmed that there are three flow regions at the low inlet gas flow rate: inlet, bulk and exit. The most complex region is the bulk region because it consists of bubble breaking-up and coalescence, as well as overlapping. The inlet region has nearly the same height as the exit region. This height equals about one-quarter of the total liquid height. About a half of the liquid height was for the churn-turbulent bulk region. At the inlet region, bubble diameter was a function of the inlet gas volumetric flow rate or the Reynolds number. The inlet gas Reynolds numbers in addition to the orifice sizes affected bubble vertical velocity or bubble Reynolds number. The mother-to-daughter bubble number ratio was a function of both the inlet gas Reynolds number. The heat transfer between the gas bubbles and their surrounding liquid increased as the increase of inlet gas temperature ratio.

\section{Acknowledgments}

The authors gratefully acknowledge the support of Peak3 P/L in collaboration with ARC Linkage grant LP110200158.

\section{References}

[1] Abdulwahid, A.A., Situ, R., Brown, R. (2018) Underground diesel exhaust wet scrubbers: Current status and future prospects. Energies, 11, 1-20. doi:10.3390/en1111306.

[2] Abdulwahid, A.A., Situ, R., Brown, R. (2018) Heat and mass transfer process in exhaust wet scrubber, $21^{s t}$ Australasian Fluid Mech. Conf. $10^{\text {th }}-13^{\text {th }}$ Dec. 2018, Australia.

[3] Clift, R., Grace, J. R., Weber, M. E. (1978) Bubbles, drops and particles, Academic press Inc., New York.

[4] Harris, P.J.; Al-Awadi, H.; Soh, W.K. (2004) An investigation into the effects of heat transfer on the motion of a spherical bubble. ANZIAM J. 45, 361-371.

[5] Funada, T., Joseph, D. D., Maehara, T., Yamashita, S., 2005, Ellipsoidal model of the rise of a Taylor bubble in a round tube, International Journal of Multiphase Flow, 31 (4), pp. 473-491.

[6] Besagni, G., Inzoli, F., The effect of liquid phase properties on bubble column fluid dynamics: Gas holdup, flow regime transition, bubble size distributions and shapes, interfacial areas and foaming phenomena. Chem. Eng. Sci., 2017, 160, pp. 270296

[7] Hart, W.F., (1976) Heat transfer in bubble-agitated system. A general correlation. Ind. Eng. Chem., Process Des., 15, 109-114. 